Original Research Paper

\title{
Instructional Methods to Computer Science Education as Investigated by Computer Science Teachers
}

\author{
Andreas Zendler and Dieter Klaudt \\ Institute of Mathematics and Computer Science, University of Education Ludwigsburg, Germany
}

Article history

Received: 11-09-2014

Revised: 16-11-2015

Accepted: 18-11-2015

Corresponding Author:

Andreas Zendler

Institute of Mathematics and

Computer Science, University

of Education Ludwigsburg,

Germany

E-mail: zendler@ph-ludwigsburg.de

\begin{abstract}
Answers to the questions of which instructional methods are suitable for school, what instructional methods should be applied in teaching individual subjects and how instructional methods support the act of learning represent challenges to general education and education in individual subjects. This article focuses on computer science teachers' examination of instructional methods supporting knowledge processes in the act of learning. A survey was conducted in which computer science teachers evaluated 20 instructional methods in regard to the following knowledge processes: Build, process, apply, transfer, assess and integrate. The results of the study show that certain instructional methods are especially predestined for computer science education: Problem-based learning, learning tasks, discovery learning, computer simulation, project work and direct instruction.
\end{abstract}

Keywords: Computer Science Education, Teaching Methods, Instructional Methods, Act of Learning, Knowledge Processes

\section{Introduction}

Answers to the questions of which instructional methods are suitable for school, what instructional methods should be applied in teaching individual subjects and how instructional methods support the act of learning represent challenges to general education and education in individual subjects. The wide range of instructional methods is almost incomprehensible. The associated literature describes a broad spectrum of instructional methods ranging from methods of conveying and acquiring knowledge to management methods for games, movement, emotions, groups, health, violence and conflicts.

CTL (2015) cites 150 instructional methods, Gugel (2011) more than 2,000 methods including their variations. There are well-prepared monographs of instructional methods available (e.g., Ginnis, 2001; Petrina, 2006; Joyce et al., 2008; Davis, 2009; Petty, 2009; Brenner and Brenner, 2011; Cruickshank et al., 2011). The monograph from Joyce et al. (2008) is helpful in bringing order to the variety of concepts, with classifications of the instructional methods for teaching families (social interaction family, information processing family, personal family, behavioral modification family).

Meyer (2002) is a source of a very general definition stating that instructional methods are the forms and procedures with which teachers and school pupils appropriate the natural and social reality surrounding them while observing the institutional framework conditions of the school. There are very divergent views of what an instructional method is according to its general definition. There are also numerous synonyms depending on whether instructional methods are addressed in the context of learning forms, teaching forms or teaching approaches and principles. A stricter definition of method (than the one formulated above) which also represents the conceptual starting point for this article comes from Huber and Hader-Popp (2007): "The word method is understood to mean a clearly defined, conceptually perceivable and independent, if also integrated, component of teaching." (Huber and Hader-Popp, 2007).

Many theoretical learning/teaching approaches make a distinction between phases/processes/cycles for which instructional methodology aids are formulated; overviews of such are provided by Tennyson et al. (1997) and Petrina (2006). For instance, Merill (2002) suggests that the most effective learning environments are those that are problem-based and involve the student in four distinct phases of learning: (1) Activation of prior experience, (2) demonstration of skills, (3) application of skills and (4) integration or these skills into real world activities. 
The theory from Collins et al. (1989), which has situated learning at its core, reveals four main phases: Modeling, scaffolding, fading and coaching. Cognitive oriented approaches (Bruner, 1966; Gagné et al., 2004) link instruction to the acquisition and processing of knowledge. They emphasize three (cognitive/knowledge) processes in the act of learning: Acquisition of new information, transformation (manipulating knowledge to make it fit new tasks), evaluation (checking whether the way we have manipulated information is adequate to the task) (see Bruner, 1966; Merriam and Caffarella, 2006; Gowda, 2010).

Several articles in the computer science educational magazine LOG IN are interesting from methodological and practical teaching points of view. LOG IN already raised awareness of the necessity of new instructional methods in computer science education twelve years ago (Seiffert and Koerber, 2003). Among the publications found in the LOG IN heading 'Practice and Methodology' there are more than 20 reports featuring the following instructional methods: Direct instruction, inductive approaches, research-based learning and the experiment method, concept mapping, discovery learning, problem solving, self-directed learning, project teaching; simulation and modeling and role-play (LOG IN, 2006; 2015).

The search through the magazines and conference reports on computer science education (ACM Transaction on Computing Education, Computer Science Education, Journal of Educational Computing Research, Special Interest Group Computer Science Education Bulletin) provided findings related to computer science education in regard to constructivist teaching activities (Mark and Grissom, 2001), the "eXtreme teaching" approach (Andersson and Bendix, 2006), holistic teaching and learning (Thota and Whitfield, 2010), the influence of instructional methods on the design of computer programs (Hung, 2012), the effect of games on motivation in teaching (Freitas and Freitas, 2013), the reduction of learning content (Kilpeläinen, 2010), the application of formal modeling (Barnett and Windley, 2006; Carro et al., 2013), the effectiveness of two-person team programming (Braught et al., 2011), the effectiveness of cooperative learning instructional methods (Beck and Chizhik, 2013) and the application of the experiment (Schulte, 2012).

Whereas the curricula from ACM $(2003 ; 2008 ; 2013)$ contains no statements regarding instructional methods, the 'Computer Science Educational Standards for Secondary Education Stage I' (Torsten, 2008) recommend various instructional methods (e.g. direct instruction, project, group and free work) and learning forms (e.g., subject-related, interdisciplinary, selfdirected learning).
There are numerous empirical findings on the effectiveness of learning. In his compilation drawing on 800 meta-analyses into which more than 50,000 studies were included Hattie (2009) provides information on the influences on learning with respect to six domains: Contributions of the person learning, the parental home, the school, the instructor, the curricula and teaching. In particular, the domain of teaching (Hattie, 2009, Chapter 9 and 10) provides information on the effectiveness of instructional methods/approaches. High effect sizes $(d>0.50)$ were demonstrated for microteaching $(d=0.88)$, reciprocal teaching $(d=$ $0.74)$, feedback $(d=0.73)$, problem solving $(d=$ $0.61)$, direct instruction $(d=0.59)$, mastery learning $(d=0.58)$, case study $(d=0.57)$, concept mapping $(d$ $=0.57)$, peer tutoring $(d=0.55)$, cooperative (Vs. competitive) learning $(d=0.54)$ and interactive instructional videos $(d=0.52)$.

The available educational literature provides specific information in response to the question regarding which instructional methods are to be applied in teaching individual subjects, e.g., Choudhary (2004) for biology, Knight (2002) for physics as well as Bennet and Hibbs (2007) for mathematics. Textbook publisher Cornelsen (2015) has published secondary education methodological manuals for 14 educational subjects in its 'Methodology' series, but none for the subject of computer science.

There is as yet no standard reference work for computer science education which extensively addresses the application of instructional methods for school. The literature contains descriptions on the application of solving problems (Koffmann and Brinda, 2003; Hubwieser, 2013), group work (Iron et al., 2004), rich tasks, concept-mapping (Hazzan et al., 2011), pattern-oriented instruction (Muller and Haberman, 2008), lab-centered instruction (Titterton et al., 2010), discovery learning and project teaching (Hartmann et al., 2006) and visualizations (Fincher and Petre, 2004; Agneli et al., 2013).

In view of the fact that there is little empirical material to date on instructional methods in computer science education, three objectives have been at the forefront of the interest of a research project at the Institute of Mathematics and Computer of the University of Education Ludwigsburg: (1) An inventory of computer science instructional methods: What instructional methods are currently in use in computer science education?, (2) Instructional methods for the subject of computer science: What instructional methods are appropriate for computer science education? and (3) Specific application of instructional methods for the subject of computer science: To what degree do instructional methods 
support the act of learning in computer science education?

The following research hypothesis is linked with these three objectives: "Instructional methods for the subject of computer science differ in supporting the act of learning with respect to computer science teachers' opinions."

This article is structured as follows: The content in section 2 consists of the (research) methods applied, describing the study design and procedures as well as the data analysis strategy. Then, we give a detailed account of our findings. In the last section we discuss the findings and, finally, draw implications.

\section{Method}

\section{Research Design}

\section{Selection of Instructional Methods}

The review of a series of instructional methods manuals (Ginnis, 2001; Petrina, 2006; Davis, 2009; Joyce et al., 2008; Petty, 2009; Brenner and Brenner, 2011; Cruickshank et al., 2011) revealed more than 50 instructional methods to choose from. The review was characterized by the requirement that instructional methods had to pass the muster as being capable of being understood as clearly defined, conceptually perceivable and independent components of the instruction.

The following criteria were applied for the final selection of the instructional methods: (1) The actual application of the instructional methods in computer science education, (2) the application of the instructional methods in science subjects (mathematics, informatics, natural sciences and technology) and (3) empirically examined instructional methods. The following 20 instructional methods (in alphabetical order) were able to be selected on the basis of these criteria: Case study, computer simulation, concept mapping, direct instruction, discovery learning, experiment, guidelines text method, jigsaw method, learning at stations, learning by teaching, learning tasks, models method, portfolio method, presentation, problem-based learning, programmed instruction, project work, reciprocal teaching, role-play and web quest (see Appendix A. Instructional Methods).

\section{Processes Involved in the act of Learning}

There are numerous variations in educational literature relating teaching to learning as an act spread over time and to phases which can be distinguished during the course of learning (Bruner, 1966; Petrina, 2006; Olson, 2007; Davis, 2009). What all of the variations have in common is that learning (1) has a starting point, (2) a sequential form and (3) a (generally preliminary) end point. Educational literature describes this as the classic three-step pattern divided into the steps labeled entry, work phase and graduation. These three steps have particularly large distinctions in their educational functions and in the knowledge processes of the act of learning. Particularly in the work phase, important knowledge processes (Bruner, 1966; Merriam and Caffarella, 2006; Gowda, 2010) can be distinguished in the act of learning. This indicates the processes in the acquisition of knowledge (build, process), in the transformation of knowledge (apply, transfer) and in the evaluation of knowledge (assess, integrate) (see Appendix B. Knowledge Processes).

\section{Experimental Design}

An RBF-20×6 experimental design (Randomized Block Factorial design, 2-factor design with repeated measures, Fig. 1) is used to test the research hypothesis (Winer et al., 1991; Kirk, 2012).

\section{Independent Variables}

Factor $A$ comprises the $p=20$ instructional methods with factor levels $a_{1}, \ldots, a_{20}$ : Case study, computer simulation, concept mapping, direct instruction, discovery learning, experiment, guidelines text method, jigsaw method, learning at stations, learning by teaching, learning tasks, models method, portfolio method, presentation, problem-based learning, programmed instruction, project work, reciprocal teaching, role-play and web quest. Factor $B$ represents the $q=6$ knowledge processes with factor levels $b_{1}, \ldots, b_{6}$ : Build, process, apply, transfer, assess and integrate.

\section{Dependent Variables}

The dependent variable was the respondents' evaluation of the instructional methods with respect to the six knowledge processes. Ratings were given on a six-point scale with ratings ranging from 0 ("not significant") to 5 ("very significant").

\section{Power Analysis}

The sample size for the RBF-20×6 experimental design (Mueller and Barton, 1989; Mueller et al., $1992)$ is determined with a type II power analysis - $N$ as a function of power $(1-\beta), \Delta$ and $a$. The desired power $(1-\beta)$ is 0.80 and only large effects $(\Delta=0.80)$ in relation to the dependent variable are classified as significant; the significance level is $a=0.05$. Then a total sample of approximately $N^{*}=120$ computer science teachers is needed, based on the power calculations by Mueller and Barton (1989), respectively, by Mueller et al. (1992) for $\varepsilon$-corrected $F$-Tests. 


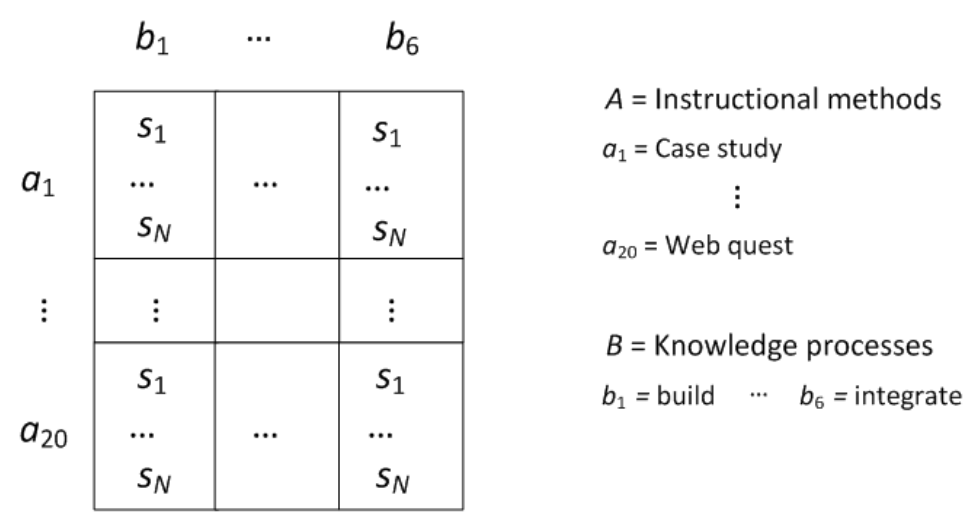

Fig. 1. Layout of the used RBF- $20 \times 6$ experimental design

\section{Operational Test Hypothesis}

Given the study design and the above specification of the independent and dependent variables, the operational hypothesis of the study can be formulated as follows: "Instructional methods for the subject of computer science differ in supporting the act of learning with respect to computer science teachers' opinions, as operationalized by computer science teachers' ratings on a six-point scale of the knowledge processes build, process, apply, transfer, assess and integrate."

\section{Procedure}

\section{Sample}

For the empirical study, a total of 120 computer science teachers working at secondary schools in the German State of Baden-Württemberg were contacted in writing and asked to fill out a questionnaire on the application of instructional methods in computer science education. The computer science teachers who completed and returned the questionnaire taught computer science in the grade levels 11 and 12/13. On average they had taught computer science for approximately 7.5 years; in addition to teaching computer science, all of the computer science teachers also taught the subject of mathematics.

\section{Questionnaire}

The questionnaire consisted of a short introduction listing the 20 instructional methods and the 6 knowledge processes. The questionnaire was accompanied by a booklet (Author, 2014; 2015) for the teachers describing the 20 instructional methods in accordance with a uniform scheme containing (1) a brief description and explanation, (2) concrete execution steps, (3) and examples from the relevant literature verifying the application of the instructional method in computer science education.

\section{Tasks}

The $p=20$ instructional methods and the $q=6$ knowledge processes were then presented in alphabetical order in a matrix with the instructional methods in the rows and the knowledge processes in the columns. Participants were asked to indicate the relevance of each of the $20 \times 6=120$ matrix cells: Each cell represents a combination of an instructional method and a knowledge process and requires an integer from 0 ("not significant") to 5 ("very significant") indicating the relevance of the combination (see Appendix C. Questionnaire).

\section{Return Rate}

To maximize the return rate, we mailed the questionnaire in sealed, personalized envelopes enclosing a pre-addressed return envelope franked with stamps showing flower designs (see Dillman, 2000 for recommendations on increasing return rates). The return rate was $20 \%(N=24$ completed questionnaires of 31 received questionnaires), which can be regarded as a normal rate for surveys conducted by post (cf. Vaux and Briggs, 2005).

\section{Data Analysis}

The following procedure is recommended for the analysis of the experimental data (original data, see Appendix D. Data): (1) The data are initially analyzed descriptively. (2) Then a two-factor Analysis of Variance (ANOVA) with repeated measures was conducted in accordance with the RBF-20 $\times 6$ experimental design (see Winer et al., 1991, Chapter 7). (3) Finally, a cluster analysis is calculated aimed at identifying groups of instructional methods which can be characterized by their support of similar knowledge processes in the act of learning.

The data on the RBF- $20 \times 6$ experimental design were analyzed using IBM SPSS Statistics 22.0; the power analysis was calculated using PASS 13. 


\section{Results}

\section{Descriptive Findings}

The heat map seen in Fig. 2 contains the means $(N=24)$ for the 20 instructional methods with respect to the six knowledge processes: Build, process, apply, transfer, assess and integrate. The figure also contains the grand means of the instructional methods with respect to the means of the knowledge processes. The instructional methods are sorted in accordance with these grand means.

Figure 2 shows initially that problem-based learning was assessed by the computer science teachers as the best method for supporting the act of learning in computer science education; this method is followed by five additional instructional methods: Learning tasks, discovery learning, computer simulation, project work method and direct instruction.

In a more detailed observation the heat map reveals that problem-based learning is distinguished by high values $(>3.50)$ for all knowledge processes. The instructional method learning tasks is characterized by high values for the knowledge processes of process and apply. The discovery learning instructional method demonstrates high values for the knowledge process build. Particularly high values $(>4.00)$ for the knowledge process build are shown by the direct instruction instructional method, which additionally has relatively high values $(>3.00)$ for the knowledge processes process and apply. Whereas the computer simulation instructional method is characterized by relatively high values for the first four knowledge processes, the project work method is notable for relatively high values with the knowledge processes apply, transfer and assess.

The following instructional methods in the heat map are also noteworthy: The models method due to its relatively high values in the knowledge process apply, programmed instruction due to its relatively high values in the knowledge processes build, process and apply, learning at stations due to its relatively high values in the knowledge process of process and finally presentation and the experiment method due to their relatively high values in the knowledge process build.

The following instructional methods had relatively low values in all of the knowledge processes $(<3.00)$ : Learning by teaching, case study, the jigsaw method, concept mapping and the guidelines text method. Web quest, reciprocal teaching and the portfolio method were rated as relatively poor $(<2.50)$ in all of the knowledge processes.

\section{Analysis of Variance}

To examine whether the combinations of instructional methods and knowledge processes within the act of learning differ, three statistical hypotheses are formulated which are tested at the significance level of $\alpha=0.05$.

\section{Statistical Hypotheses}

The three null hypotheses are as follows:

- The means of the instructional methods $\mu_{1}, \mu_{2}, \ldots$, $\mu_{20}$ under the 20 levels of factors $A$ are equal, i.e.:

$H_{0}: \mu_{1}=\mu_{2}=\ldots=\mu_{20}$

- The means of the knowledge processes in the act of learning $\mu_{1}, \mu_{2}, \ldots, \mu_{6}$ under the 6 levels of the factor $B$ are equal, i.e.:

$H_{0}: \mu_{1}=\mu_{2}=\ldots=\mu_{6}$

- The means of the instructional methods with respect to the knowledge processes $\mu_{1 \times 1}, \mu_{1 \times 2}, \ldots, \mu_{20 \times 6}$ under the $20 \times 6$ levels of the factor combinations $A \times B$ are equal, i.e.:

$H_{0}: \mu_{1 \times 1}=\mu_{1 \times 2}=\ldots=\mu_{20 \times 6}$

\section{Testing the Statistical Assumptions}

For an analysis of variance of an RBF-20×6 experimental design, the data must satisfy the condition of sphericity. This assumption was tested using Mauchly's $W$ test for sphericity, with the test statistic $W$ being compared to a chi-square distribution to assess the adequacy of the sphericity assumption. The assumption of sphericity must be discarded both for the instructional methods $\left(W<0.001, \chi_{189}^{2}=268.86\right.$, $p<0.001)$ and also for the processes of the acquisition of knowledge $\left(W=0.116, \chi_{14}^{2}=45.53, p<0.001\right)$ at the $\alpha$-level of 0.05 . In the further analysis, we therefore applied the $\varepsilon$-correction of degrees of freedom proposed by Huynh and Feldt (1976).

\section{Findings}

Table 1 contains the results of the ANOVA with the $\varepsilon$-correction of the degrees of freedom.

The main effect $A$ (instructional methods) is significant $\left(F_{16,363}=8.33, p<0.001\right)$ at the $\alpha$-level of 0.05 , i.e., the corresponding $H_{0}$ is rejected: The instructional methods differ from one another.

The main effect $B$ (knowledge processes) is significant $\left(F_{3,73}=14.11, p<0.001\right)$ at the $\alpha$-level of 0.05 , i.e., the corresponding $H_{0}$ is rejected: The knowledge processes differ from one another.

The interaction effect $A \times B$ (instructional methods $\times$ knowledge processes) is significant $\left(F_{21491}=5.00\right.$, $p<0.005$ ) at the $\alpha$-level of 0.05 , i.e., the corresponding $H_{0}$ is rejected: The instructional methods differ from one another with respect to knowledge processes. 


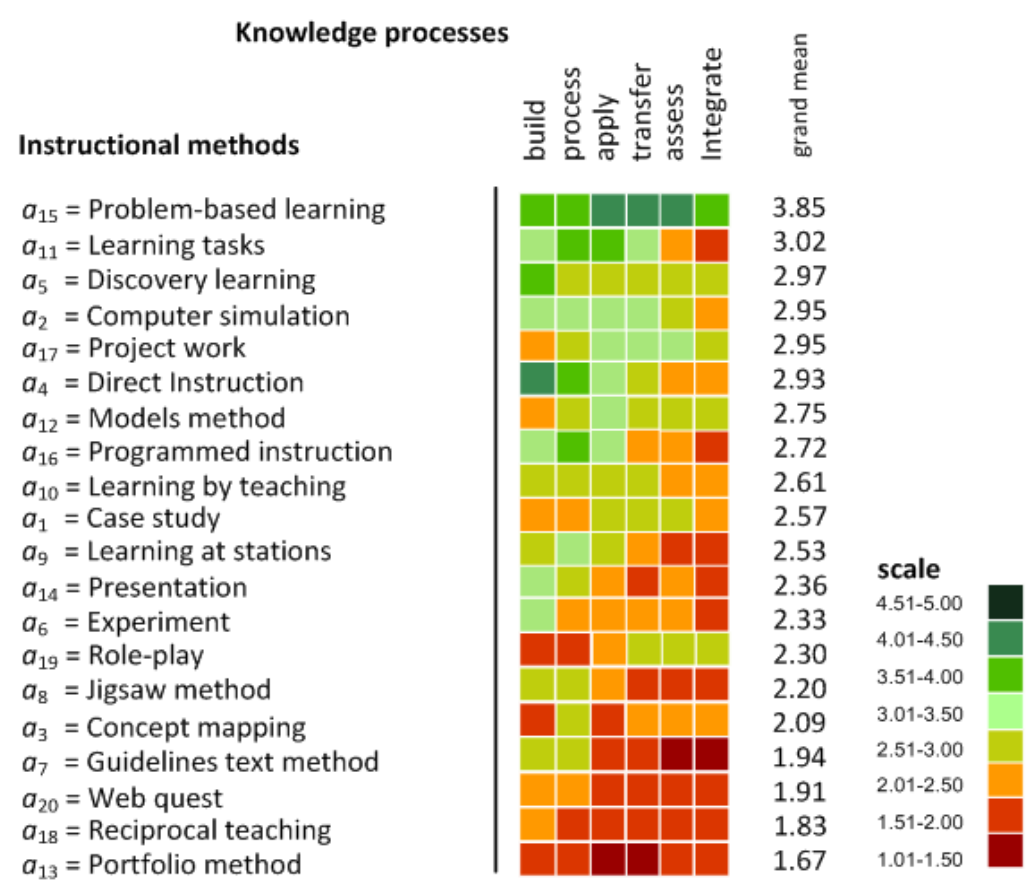

Fig. 2. Means of the instructional methods visualized for the knowledge processes

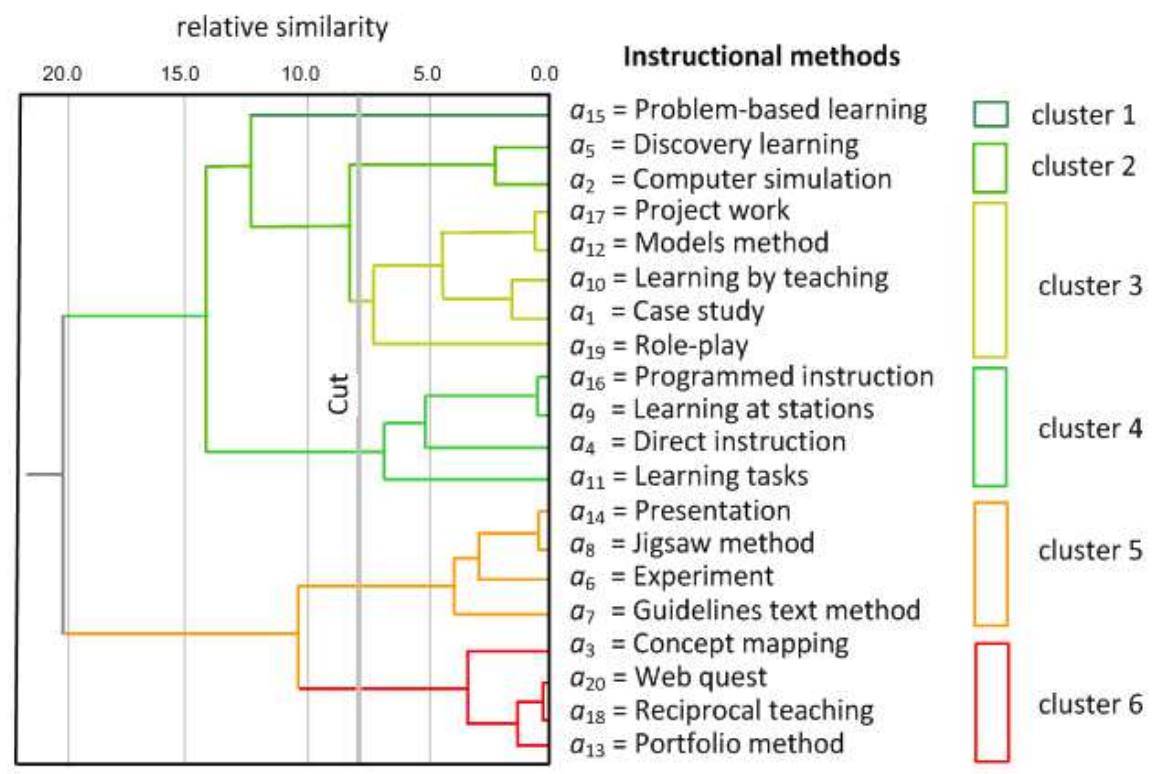

Fig. 3. Dendrogam and clusters of instructional methods $(\mathrm{N}=24)$

Table 1. ANOVA with Huynh-Feldt $\varepsilon$-correction of the degrees of freedom

\begin{tabular}{lrrrrrl}
\hline Source of variation (within) & \multicolumn{1}{c}{$S S$} & $d f$ & $M S$ & $F$ & $p$ & $\eta 2$ \\
\hline A (instructional methods) & 742.22 & 16 & 47.02 & 8.33 & $<0.001$ & 0.266 \\
Error (A) & 2048.98 & 363 & 5.64 & & & \\
B (knowledge processes) & 143.22 & 3 & 44.86 & 14.11 & $<0.001$ & 0.380 \\
Error $(B)$ & 233.40 & 73 & 3.18 & & & \\
A $\times B$ & 450.94 & 21 & 21.11 & 5.00 & $<0.005$ & 0.178 \\
Error $($ A $\times B$ ) & 2075.56 & 491 & 4.23 & & & \\
\hline
\end{tabular}




\section{Cluster Analysis}

The alphabetically sorted $20 \times 6$ data matrix (see Appendix D. Data) with the means of the instructional methods in regard to the knowledge processes is taken as the data basis for the cluster analysis. The cluster analysis has been done using the method of Ward (1963) with squared Euclidean distance as distance measure (Everitt et al., 2001). For the termination of the algorithm, the C-Index (Hubert and Levin, 1976) has been taken into consideration (this is visualized as "cut" in the figures).

Figure 3 shows the results of the cluster analysis for the instructional methods. The dendrogram reveals that six clusters with instructional methods emerged. Cluster 1 is particularly notable in the dendrogram because it only contains one instructional method, namely problembased learning.

\section{Cluster 1}

This cluster contains only problem-based learning as its sole instructional method. It is characterized by high values for the knowledge processes build, process apply, transfer, assess and integrate. The dendrogram shows that this instructional method cannot be merged with other instructional methods due to the value for the $\mathrm{C}$ index (see "Cut" in Fig. 3).

\section{Cluster 2}

This cluster contains the two instructional methods of discovery learning and computer simulation. These methods are characterized by values that are still high in regard to the knowledge processes build, process, apply, transfer and assess, whereby discovery learning is distinguished by high values in the acquisition of knowledge process build.

\section{Cluster 3}

This cluster contains the most instructional methods. It is comprised of the following five instructional methods: Project work, models method, learning by teaching, case study and role-play. Some of these are distinguished by the fact that they still have high values in the knowledge process of apply. The project work method is interesting, demonstrating still high values in the knowledge processes of apply, transfer and assess.

\section{Cluster 4}

This cluster consists of four instructional methods: Programmed instruction, learning at stations, direct instruction and learning tasks. The cluster is notable for its relatively high values in the knowledge processes build, process and apply. Special note must be given to direct instruction which demonstrates very high values in the knowledge process of build and to learning tasks which demonstrates high values in the knowledge processes build, process, apply and transfer.

\section{Cluster 5}

This cluster comprises four instructional methods: Presentation, jigsaw method, experiment method and the guidelines text method. The instructional methods in this cluster are characterized by low values in regard to the knowledge processes apply, transfer, assess and integrate.

\section{Cluster 6}

This cluster is the most homogenous cluster in the cluster solution for the instructional methods and consists of four instructional methods: Concept mapping, web quest, reciprocal teaching and the portfolio method. The instructional methods in this cluster are characterized by low values in regard to all of the knowledge processes.

\section{Discussion}

It must first be noted that the findings support the research hypothesis formulated in this paper's introduction that instructional methods for the subject of computer science differ in supporting the act of learning with respect to computer science teachers' opinions.

In the opinions of the computer science teachers, problem-based learning seems to perform best in relation to almost all of the knowledge processes, learning tasks are well suited for the $\alpha$-level of 0.05 , i.e., the corresponding $H_{0}$ is rejected: The useful for three knowledge processes (apply, transfer, assess). Direct instruction is the instructional method most suitable for the knowledge process build; it is also suitable for the knowledge processes process and apply. The models method and programmed instruction can be used for the knowledge process apply; programmed instruction is additionally well suited for the knowledge process process. Presentation and the experiment method are well suited for the knowledge process build, while learning at stations is appropriate for process. The roleplay instructional method is interesting as it better supports the final three knowledge processes transfer, assess and integrate than the first three knowledge processes build, process and apply. The instructional methods that are unsuitable for computer science education are web quest, reciprocal teaching and the portfolio method.

Conversely, these findings also answer the question regarding what knowledge processes are adequately supported by which instructional method. It must first be noted that the knowledge processes in the act of learning are supported by the instructional methods in wholly 
different ways. The knowledge process build is supported by the instructional methods problem-based learning, discovery learning, computer simulation, programmed instruction, direct instruction, learning tasks, presentation and the experiment method. The situation is similar for the knowledge process process which is positively influenced by the instructional methods problem-based learning, computer simulation, programmed instruction, learning at stations, direct instruction and learning tasks. The knowledge processes apply and transfer are supported in particular when the instructional methods problembased learning, computer simulation, project work method, the models method and learning tasks are applied. The knowledge processes assess and integrate are supported by fewer instructional methods: They are appropriate for the knowledge process assess and at least two more instructional methods, namely problem-based learning and the project work method. Only problem-based learning remains for the knowledge process integrate.

The first three knowledge processes (build, process, apply) receive significantly greater support from the instructional methods than the last three knowledge processes (transfer, assess, integrate). The knowledge process assess is only relatively well supported by two instructional methods (problem-based learning, project work), while the knowledge process integrate is only supported by one instructional method (problem-based learning).

\section{Conclusion}

Based on the opinions of the computer science teachers, the following recommendations can be expressed for the application of instructional methods in computer science education: (1) For the knowledge process of build direct instruction should be used in combination with problem-based learning and augmented by learning tasks in order to initiate the knowledge process of process. (2) For the knowledge process of apply, problem-based learning should be used in combination with learning tasks. (3) To support the knowledge processes of transfer, assess and integrate, problem-based learning should be used and supported by the project work method (transfer, assess) and the role-play (transfer, assess, integrate). (4) To introduce diversity into computer science education and to increase the motivation of the learners it is recommended to use instructional methods in a substituting role to the extent that they support similar knowledge processes. It can for instance be derived from the cluster analysis and the heat map that the project work method and the models method are similar in their relation to the knowledge processes, as are programmed instruction, learning at stations, discovery learning and computer simulation.

The findings determined in this study on the application of instructional methods in computer science education confirm the recommendations made in standard works on the subject of computer science education. This applies for the instructional methods problem-based learning, learning tasks, discovery learning, computer simulation, the project work method and the models method favored in the standard works (Koffmann and Brinda, 2003; Iron et al., 2004; Hartmann et al., 2006; Hubwieser, 2013; Hazzan et al., 2011). Some of the findings on what are generally referred to as instructional methods in the literature can be applied to computer science education, e.g. the positive effect sizes of direct instruction and case study (Hattie, 2009). In contrast, the positive findings cited by the literature on the instructional method of reciprocal teaching are not applicable. This method is unsuitable for computer science education.

The data from computer science teachers who teach at secondary schools was able to be included in the study. In order to verify and validate the results of these findings an examination should take place in authentic teaching and learning settings and should not be based on subjective opinions. Instructional methods assessed in this study as being very unfavorable for computer science education such as web quest, reciprocal teaching and the portfolio method do not need to be observed further.

Moreover, the findings in this study showed that the knowledge processes assess and integrate are only adequately supported by one instructional method, namely problem-based learning. As such, the field of developing methods for computer science education is faced with the task of developing instructional methods which support these knowledge processes in the act of learning. In the authors' opinion, the starting point for the development of such instructional methods can be found within the context of competence-based learning tasks and in cross-curricular instruction.

\section{Acknowledgment}

We thank NataschaTreter and Sarah Barbara Leopold for their support in preparing the survey. The project was funded by Ludwigsburg University of Education.

\section{Author's Contributions}

All authors equally contributed in this work.

\section{Ethics}

This article is original and contains unpublished material. The corresponding author confirms that all of 
the other authors have read and approved the manuscript and no ethical issues involved.

\section{References}

Abell, S.K. and N.G. Lederman, 2007. Handbook of Research on Science Education. 1st Edn., Lawrence Erlbaum, New York.

ACM, 2003. A Model Curriculum for K-12 ACM Computer Science. 1st Edn., ACM, New York.

ACM, 2008. Computer Science Curriculum 2008. 1st Edn., ACM, New York.

ACM, 2013. Computer Science Curriculum 2013. 1st Edn., ACM, New York.

Agneli, C., D. Kadijevich and C. Schulte, 2013. Improving Computer Science Education. 1st Edn., Routledge Chapman and Hall, London.

Aldrich, C., 2009. Simulations and Serios Games. 1st Edn., San Francisco Pfeiffer.

Andersson, R. and L. Bendix, 2006. eXtreme teaching: A framework for continuous improvement. Comput. Sci. Educ., 16: 175-184.

Aronson, E., 1978. The Jigsaw Classroom. 1st Edn., Sage Publications, Beverly Hills.

Barnett, M. and P. Windley, 2006. Dysfunctional programming: Teaching programming using formal methods to noncomputer science. Comput. Sci. Educ., 5: 111-122.

Beck, L. and A. Chizhik, 2013. Cooperative learning instructional methods for CS1: Design, implementation and evaluation. Trans. Computing Education.

Bennet, R. and J. Hibbs, 2007. Teaching Mathematics: The Professional Guide. 1st Edn., Trans-Atlantic Publications, Oxfordshire, ISBN-10: 1844897168, pp: 353.

Biswas, G., K. Leelawong, D. Schwartz, N. Vye and the T.A.G. Vanderbilt, 2005. Learning by teaching: A new agent paradigm for educational software. Applied Artificial Intelligence, 18: 365-392. DOI: $10.1080 / 08839510590910200$

Branom, M.E., 1918. The Project Method in Education. 1st Edn., BiblioBazaar, London, ISBN-10: 0554851202, pp: 175.

Braught, G., T. Wahlks and L.M. Eby, 2011. The case for pair programming in the computer science classroom. ACM Trans. Computing Education.

Brenner, G. and K. Brenner, 2011. Lernen lehren: Methoden für alle Fächer: Sekundarstufe Iund II. 1st Edn., Cornelsen Scriptor, Berlin.

Bruner, J.S., 1966. The Process of Education. 1st Edn., Harvard University Press, Cambridge.
Canton, R.K., 2007. Programmed Instruction in Online Learning. 1st Edn., Cambia Press, Boston.

Carro, M., A. Herranz and J. Mariño, 2013. A modeldriven approach to teaching concurrency. ACM Trans. Computing Education.

Choudhary, S., 2004. Teaching of Biology. 1st Edn., APH Publishing Corporation, Tornes.

Collins, A., Brown and S.E. Newman, 1989. Cognitive Apprenticeship. Teaching the Crafts of Reading, Writing and Mathematics. In: Knowing, Learning and Instruction, L.B. Resnick (Ed.), Erlbaum, Hillsdale. pp: 453-494.

Cornelsen, 2015. Methodik.

Cruickshank, D.R., D.B. Jenkins and K.K. Metcalf, 2011. The Act of Teaching. 6th Edn., McGraw-Hill Education, New York, ISBN-10: 0078097916, pp: 560.

Davis, G.B., 2009. Tools for Teaching. 2nd Edn., John Wiley and Sons, San Francisco, ISBN-10: 047056945X, pp: 608.

Dillman, D.A., 2000. Mail and Internet Surveys: The Tailored Design Method. 1st Edn., Wiley, New York.

Everitt, B.S., S. Landau and M. Leese, 2001. Cluster Analysis. 1st Edn., Arnold, London.

Fincher, S. and M.S. Petre, 2004. Computer Science Education Research.1st Edn., Routledge Falmer, London.

Flewelling, G. and W. Higginson, 2003. Teaching with rich learning tasks: A Handbook. 2nd Edn., Australian Association Of Mathematics Teachers, Adelaide, ISBN-10: 1875900551, pp: 168.

Freitas, D.A. and M.M.D. Freitas, 2013. Classroom live: A software-assisted gamification tool. Comput. Sci. Educ., 23: 186-206. DOI: $10.1080 / 08993408.2013 .780449$

Gagné, R.M., W.W. Wagner, K. Golas and J.M. Keller, 2004. Principles of Instructional Design. 1st Edn., Wadsworth Publishing, London.

Gartner, A., M.C. Kohler and F. Riessman, 1971. Children Teach Children: Learning by Teaching. 1st Edn., Harper and Row, New York, pp: 180.

Ginnis, P., 2001. The Teacher's Toolkit: Classroom Achievement. 1st Edn., Crown House Publishing, Carmarthen.

Gowda, N.S., 2010. Learning and the Learner: Insights into the Processes of Learning and Teaching. 1st Edn., PHI Learning, Delhi.

Gugel, G., 2011. 2000 Methoden für Schule und Lehrebildung. 1st Edn., Beltz, Weinheim.

Hartmann, W., M. Näf and R. Reichert, 2006. Informatikunterricht Planen und Durchführen. 1st Edn., Springer, Berlin.

Hattie, J., 2009. Visible Learning. 1st Edn., Routledge, New York. 
Hazzan, O., T. Lapidot and N. Ragonis, 2011. Guide to Teaching Computer Science: An Activity-Based Approach. 1st Edn., Springer, New York, ISBN-10: 1447166302, pp: 296.

Huber, S.G. and S. Hader-Popp, 2007. Unterrichtsentwicklung Durch Methodenvielfalt Im Unterricht Fördern: Das Methodenatelier als Schulinterne Fortbildung. In: Praxis Wissen Schulleitung, Bartz, A., J. Fabian, S.G. Huber, C. Kloft and H. Rosenbusch et al. (Eds.), 1st Wolters Kluwer, München.

Hubert, L.J. and J.R. Levin, 1976. A general statistical framework for assessing categorical clustering in free recall. Psychological Bulletin, 83: 1072-1080.

Hubwieser, P., 2013. Didaktik der Informatik: Grundlagen, Konzepte, Beispiele. 1st Edn., Springer-Verlag, Berlin, ISBN-10: 3662066181, pp: 228.

Hung, Y.C., 2012. The effect of teaching methods and learning style on learning program design in webbased education systems. J. Educ. Comput. Res., 47: 409-427.

Huynh, H. and L.S. Feldt, 1976. Estimation of the Box correction for degrees of freedom from sample data in randomised block and split-plot designs. J. Educ. Stat., 1: 69-82.

Iron, S., S. Alexander and S. Alexander, 2004. Improving Computer Science Education. 1st Edn., Routledge Chapman and Hall, London.

Joyce, B., M. Weil and E. Calhoun, 2008. Models of Teaching. 1st Edn., Pearson/Allyn and Bacon Publishers, Boston, ISBN-10: 0205593453, pp: 558.

Kilpeläinen, P., 2010. Do all roads lead to Rome? (Or reductions for dummy travelers). Comput. Sci. Educ., 20: 181-199.

Kirk, E., 2012. Experimental Design. 1st Edn., Wadsworth, Belmon.

Knight, R.D., 2002. Five Easy Lessons: Strategies for Successful Physics Teaching. 1st Edn., Addison Wesley, San Francisco, ISBN-10: 0805387021, pp: 330 .

Koffmann, E. and T. Brinda, 2003. Teaching Programming and Problems Solving. In: Informatics Curricula and Teaching Methods, Cassel, L. and R.A. Reis (Eds.), Kluwer Academic Publishers, Amsterdam, pp: 125-130.

LOG IN, 2006. Es stand in LOG IN-ausgewählte beiträge zu projekten im unterricht. LOG IN, 138: 59-59.

LOG IN, 2015. Gesamtverzeichnis. LOG IN.

Mark, J.V.G. and S. Grissom, 2001. An empirical evaluation of using constructive classroom activities to teach introductory programming. Comput. Sci. Educ., 11: 247-260.
Merill, M.D., 2002. First Principles: Educational Technology. Res. Development, 50: 43-59.

Merriam, S.B. and R.S. Caffarella, 2006. Learning in Adulthood: A Comprehensive Guide. 1st Edn., Bass, New York.

Meyer, H., 2002. Unterrichtsmethoden. In: Einführung in Die Schulpädagogik, Kiper, H., H. Meyer and W. Topsch, (Eds.), Cornelsen, Berlin, pp: 109-121.

Mueller, K.E. and C.N. Barton, 1989.Approximate power for repeated-measures ANOVA lacking sphericity. J. Am. Stat. Assoc., 84: 549-555.

Mueller, K.E., L.E. LaVange, S.L. Ramey and C.T. Ramey, 1992. Power calculations for general linear multivariate models including repeated measures applications. J. Am. Stat. Assoc., 87: 1209-1226.

Muller. O. and B. Haberman, 2008. Supporting abstraction processes in problem solving through pattern-oriented instruction. Comput. Sci. Educ., 18: $187-212$.

Novak, J.D., 1990. Concept mapping: A useful tool for science education. J. Res. Sci. Teach., 27: 937-949.

Olson, D.R., 2007. Jerome Bruner: The Cognitive Revolution in Educational Theory. 1st Edn., Bloomsbury Academic, London, ISBN-10: 1472518861, pp: 224.

Palincsar, A.S. and A.L. Brown, 1984. Reciprocal teaching of comprehension, fostering and monitoring activities. Cognit. Instruct., 1: 117-175.

Petty, G., 2009. Teaching Today: A Practical Guide. 4th Edn., Nelson Thornes, Cheltenham, ISBN-10: 1408504154, pp: 614.

Petrina, S., 2006. Advanced Teaching Methods for the Technology Classroom. 1st Edn., Idea Group Inc., Hershey, ISBN-10: 1599043394, pp: 412.

Rottluff, J., 1989. Die Leittextmethode. In: Lernen Nach der Neuordnung, Pahl, J.P. and H.D. Schulz, (Eds.), Wetzlar.

Schulte, C., 2012. Uncovering structure behind function: The experiment as teaching method in computer science education. Proceedings of the Workshop in Primary and Secondary Computing Education, (WPS' 12), New York Wiley, pp: 40-47.

Seiffert, M. and B. Koerber, 2003. Neue methoden braucht der unterricht. LOG IN, 138: 3-3.

Sims-Knight, J.E. and R.L. Upchurch, 1993. Teaching object-oriented design without programming: A progress report. Comput. Sci. Educ., 4: 135-156.

Tennyson, R., F. Schott, N. Seel and S. Dijkstra, 1997. Instructional Design: International Perspective: Theory, Research and Models. 1st Edn., Routledge, ISBN-10: 0805813977, pp: 475.

CTL, 2015. 150 Teaching Methods. CTL. 
Thota, N. and R. Whitfield, 2010. Holistic approach to learning and teaching introductory object-oriented programming. Comput. Sci. Educ., 20: 103-127.

Titterton, N., C.M. Lewis and M.J. Clancy, 2010. Experiences with lab-centric instruction. Comput. Sci. Educ., 20: 97-102.

Tomlinson, C.A., 1999. The Differentiated Classroom: Responding to the Needs of all Learners. 1st Edn., Alexandria Association for Supervision and Curriculum Development, Alexandria, ISBN-10: 1416618635, pp: 197.

Torsten, B., 2008. Grundsätze und Standards für die Informatik in der Schule: Bildungsstandards Informatik für die Sekundarstufe I; Empfehlungen der Gesellschaft für Informatik e.V. erarbeitet vom Arbeitskreis "Bildungsstandards. 1st Edn., Log-InVerlag, Berlin, pp: 62.

Vaux, A. and C.S. Briggs, 2005. Conducting Mail and Internet Surveys. In: The Psychology Research Handbook, Leong, F.T.L. and J.T. Austin, Sage, Thousand Oaks, CA, pp: 186-209.

Wankel, C. and P. Blessinger, 2012. Increasing Student Engagement and Retention Using Online Learning Activities: Wikis, Blogs and Webquests. 1st Edn., Emerald Group Publishing, Bingley, ISBN-10: 1781902372, pp: 348.

Winer, B.J., D.R. Brown and K.M. Michels, 1991. Statistical Principles in Experimental Design. 1st Edn., McGraw-Hill, Boston.

\section{Appendix}

\section{Instructional methods}

\section{Case Study}

Case study (Davis, 2009) is an instructional method aimed at the development of independent problemsolving skills by including realistic cases and tasks in the instruction.

\section{Computer Simulation}

Computer simulation (Aldrich, 2009) comprises the application of simulation software for the virtual solution of (time-related) problems.

\section{Concept Mapping}

Concept mapping (Novak, 1990) is an instructional method for the structuring and depiction of concepts and their relationships.

\section{Direct Instruction}

Direct instruction (Petty, 2009) is an instructional method with a central focus on the teacher. The teacher assumes the central role in directing the activities associated with the instruction and does not relinquish this role until the end of the learning process.

\section{Discovery Learning}

Discovery learning (Petty, 2009) is an instructional method with a central focus on the pupils in which learning recommendations are the focal point in order to motivate self-learning.

\section{Experiment}

The experiment (Abell and Lederman, 2007) as an instructional method serves in the conveyance of knowledge by making the effects of dependent variables observable through the planned variation of independent variables.

\section{Guidelines Text Method}

The guidelines text method (Rottluff, 1989) is an instructional method with which learners are guided in regard to content and methodology in such a manner that they can acquire knowledge with prepared materials.

\section{Jigsaw Method}

The jigsaw method (Aronson, 1978) is a cooperative learning instructional method in which pupils instruct their co-pupils by becoming experts on a particular topic and taking on instructional activities.

\section{Learning at Stations}

Learning at stations (Tomlinson, 1999) is a studentoriented instructional method in which pupils learn independently on the basis of prepared materials provided at workstations.

\section{Learning by Teaching}

Learning by teaching (Gartner et al., 1971; Biswas et al., 2005) is an activity-oriented instructional method in which pupils learn by teaching one another.

\section{Learning Tasks}

Learning tasks (Flewelling and Higginson, 2003) as an instructional method serve in initiating and guiding learning and thinking processes.

\section{Models Method}

The models method (Abell and Lederman, 2007) is an instructional method comprised of forming models and applying models in a particular field.

\section{Portfolio Method}

The portfolio method (Davis, 2009) is an instructional method which allows the persons learning to be aware of their own learning progress (with the help of a folder) in which they individually develop a 
conscientious approach to the quality and to their responsibility for their own learning process.

\section{Presentation}

Presentation (Petty, 2009) as an instructional method serves as verification that learners can gather, process and present information in an organized manner.

\section{Problem-Based Learning}

Problem-based learning (Abell and Lederman, 2007) is an instructional method enabling learners to acquire skills in the resolution of an exemplary problem which can then be transferred to other applicable problem areas.

\section{Programmed Instruction}

Programmed instruction is an instructional method (Canton, 2007) focusing on individualized material for the person learning to study on their own.

\section{Project Work}

The project work method (Branom, 1918) is an activities-oriented instructional method allowing learners to work on a defined objective in an organized, independent manner.

\section{Reciprocal Teaching}

Reciprocal teaching (Palincsar and Brown, 1984) is a dialogical instructional method between teachers and learners which serves as a tool in grasping the meaning of texts. There are few teaching examples cited in the relevant literature applying reciprocal teaching as an instructional method. Sims-Knight and Upchurch (1993) documented a teaching unit on object-oriented design.

\section{Role-Play}

The role-play method (Petty, 2009) is an activitiesoriented instructional method designed to promote the understanding of simple and complex activity sequences related to technology.

\section{Web quest}

Web quest (Wankel and Blessinger, 2012) is a research-oriented instructional method which includes Internet-based services (e.g., Wikipedia, portals, literature databases) and Internet technologies (e.g., E-Learning platforms, Cloud computing, Ecommunication) in the learning process.

\section{Knowledge Processes}

\section{Build}

Acquiring knowledge, new practical and cognitive abilities as well as attitudes.

\section{Process}

Establishing, deepening, structuring and connecting what has been learned.

\section{Apply}

Using what has been learned in new tasks corresponding with the framework conditions of the learning situation.

\section{Transfer}

Using what has been learned in new situations in which the framework conditions differ from those of the learning situation.

\section{Assess}

Classifying what has been learned in regard to its usefulness, scope, benefits and limits.

\section{Integrate}

Integrating what has been learned outside of the actual learning situation in connection with one's own knowledge.

\section{Questionnaire}

Please evaluate:

- The act of learning through instructional methods in computer science education

- Please rate each cell on a scale of 0 to 5 (only whole numbers)

- It is important that you provide 6 ratings per row

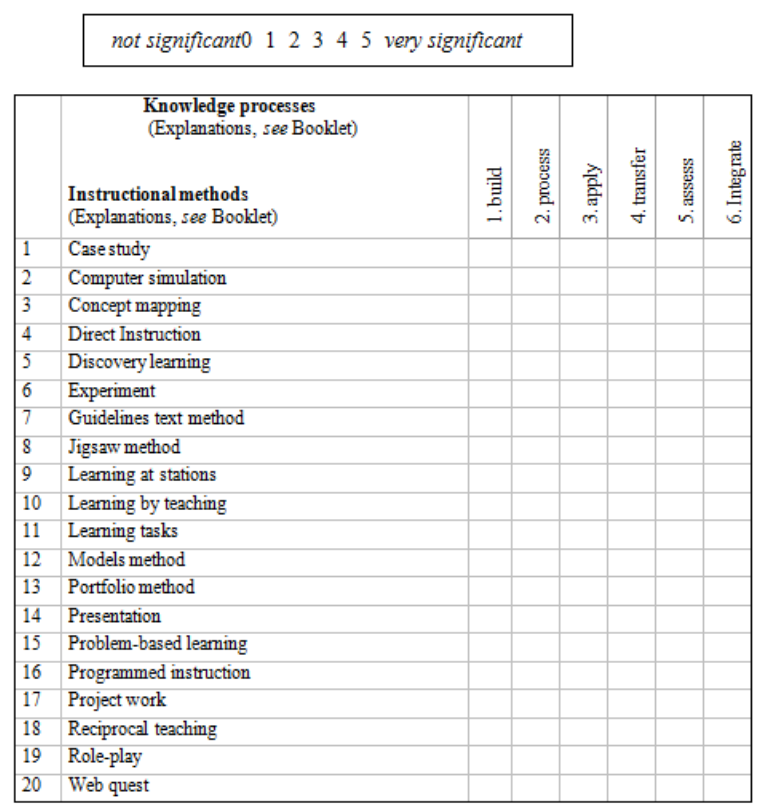

Fig. A 1. Instructional methods and knowledge processes in the act of learning 


\section{Data}

Table A1. Means of instructional methods with respect to knowledge processes $(\mathrm{N}=24)$

Knowledge processes

\section{Instructional methods}

$a_{1}=$ Case study

$a_{2}=$ Computer simulation

$a_{3}=$ Concept mapping

$a_{4}=$ Direct instruction

$a_{5}=$ Discovery learning

$a_{6}=$ Experiment

$a_{7}=$ Guidelines text method

$a_{8}=$ Jigsaw method

$a_{9}=$ Learning at stations

$a_{10}=$ Learning by teaching

$a_{11}=$ Learning tasks

$a_{12}=$ Models method

$a_{13}=$ Portfolio method

$a_{14}=$ Presentation

$a_{15}=$ Problem-based learning

$a_{16}=$ Programmed instruction

$a_{17}=$ Project work

$a_{18}=$ Reciprocal teaching

$a_{19}=$ Role-play

$a_{20}=$ Web quest

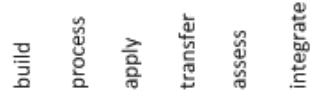

\begin{tabular}{|l|l|l|l|l|l|}
\hline 2.29 & 2.24 & 2.82 & 2.81 & 2.86 & 2.43 \\
\hline 3.23 & 3.00 & 3.14 & 3.18 & 2.73 & 2.21 \\
\hline 1.90 & 2.38 & 1.64 & 2.08 & 2.33 & 2.23 \\
\hline 4.32 & 3.55 & 3.09 & 2.55 & 2.00 & 2.09 \\
\hline 3.66 & 2.62 & 2.82 & 2.90 & 2.90 & 2.90 \\
\hline 3.35 & 2.15 & 2.42 & 2.05 & 2.10 & 1.90 \\
\hline 2.81 & 2.57 & 1.90 & 1.91 & 1.29 & 1.29 \\
\hline 2.96 & 2.91 & 2.26 & 1.70 & 1.78 & 1.57 \\
\hline 2.95 & 3.18 & 2.95 & 2.45 & 1.82 & 1.82 \\
\hline 2.73 & 2.82 & 2.86 & 2.64 & 2.41 & 2.18 \\
\hline 3.00 & 3.91 & 3.64 & 3.41 & 2.18 & 1.95 \\
\hline 2.14 & 2.64 & 3.00 & 2.95 & 2.91 & 2.86 \\
\hline 1.67 & 1.90 & 1.48 & 1.43 & 1.90 & 1.62 \\
\hline 3.10 & 2.82 & 2.36 & 1.92 & 2.00 & 1.94 \\
\hline 3.64 & 3.73 & 4.23 & 4.00 & 4.00 & 3.50 \\
\hline 3.43 & 3.61 & 3.13 & 2.43 & 2.04 & 1.70 \\
\hline 2.26 & 2.91 & 3.35 & 3.30 & 3.13 & 2.90 \\
\hline 2.10 & 1.93 & 1.74 & 1.79 & 1.74 & 1.69 \\
\hline 1.64 & 1.77 & 2.32 & 2.77 & 2.77 & 2.55 \\
\hline 2.38 & 2.18 & 1.61 & 1.75 & 1.89 & 1.66 \\
\hline & & & & & \\
\hline
\end{tabular}

